\title{
Fracture Mechanisms of Biodegradable PLA and PLA/PCL Blends
}

\author{
Mitsugu Todo ${ }^{1}$ and Tetsuo Takayama ${ }^{2}$ \\ ${ }^{1}$ Research Institute for Applied Mechanics, Kyushu University \\ ${ }^{2}$ Graduate School of Science and Engineering, Yamagata University
}

Japan

\section{Introduction}

Poly (lactic acid) (PLA), made from natural resources such as starch of plants, is one of typical biodegradable thermoplastic polymers and has extensively been used in medical fields such as orthopedics, neurosurgery and oral surgery as bone fixation devices mainly due to biocompatibility and bioabsorbability (Higashi et al., 1986; Ikada et al., 1996; Middleton \& Tipton, 2000; Mohanty, 2000). Its importance has led to many studies on its mechanical properties and fracture behavior which found that the mode I fracture behavior of PLA is relatively brittle in nature (Todo et al., 2002; Park et al., 2004, 2005, 2006). Therefore, blending with a ductile biodegradable and bioabsorbable polymer such as poly ( $\varepsilon$-caprolacton) (PCL) has been adopted to improve the fracture energy of brittle PLA (Broz et al., 2003; Dell'Erba et al., 2001; Chen et al., 2003; Todo et al., 2007; Tsuji \& Ikada, 1996, 1998; Tsuji \& Ishizuka, 2001; Tsuji et al., 2003); however, it was also found that phase separation originated by immiscibility of PLA and PCL tends to degrade the mechanical properties of PLA/PCL blends (Todo et al., 2007). It has recently been found that such phase separation can dramatically be improved by using an isocyanate group, lysine tri-isocyanate (LTI) (Takayama et al., 2006; Takayama \& Todo, 2006; Harada et al., 2007, 2008), and the fracture properties of PLA/PCL/LTI are much higher than those of PLA/PCL.

In this chapter, firstly the fracture behavior and micromechanism of pure PLA are summarized (Park et al., 2004, 2005, 2006; Todo et al., 2002). Effects of crystallization behavior and loading-rate on the mode I fracture behavior are discussed. Effect of unidirectional drawing on the fracture energy is also presented as one of the effective ways to improve the brittleness of PLA (Todo, 2007). Secondly, the fracture behavior of PLA/PCL blends is discussed on the basis of the relationship between the microstructure and the fracture property (Todo et al., 2007b). In the third section, improvement of microstructural morphology of PLA/PCL by using LTI is discussed (Takayama et al., 2006; Takayama \& Todo, 2006; Todo \& Takayama, 2007; Todo et al., 2007a). It has been found that addition of LTI effectively improves the phase morphology of PLA/PCL, resulting in dramatic improvement of fracture energy. Effects of annealing on the mechanical properties of PLA/PCL/LTI blend are discussed in the last section (Takayama et al., 2011). It has been found that a thermal annealing process can effectively improve the mechanical properties of the polymer blend, as a result of strengthened structures due to crystallization of PLA. 


\section{Fracture behavior of PLA}

\subsection{Effect of crystallization}

The microstructure of crystalline PLA can be changed through annealing process from amorphous to highly crystallized states as shown in Fig.1. $70^{\circ} \mathrm{C}-3 \mathrm{~h}$ indicates an annealing process that the specimens are kept in an oven at $70^{\circ} \mathrm{C}$ for three hours.

The annealing process of $70^{\circ} \mathrm{C}-3 \mathrm{~h}$ results in an amorphous state, on the contrary, the $100^{\circ} \mathrm{C}$ $3 \mathrm{~h}$ and $100^{\circ} \mathrm{C}-24 \mathrm{~h}$ processes create highly crystallized states and longer annealing time tends to increase the size of crystals.

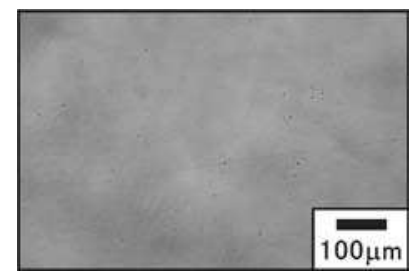

(a) $70^{\circ} \mathrm{C}-3 \mathrm{~h}$

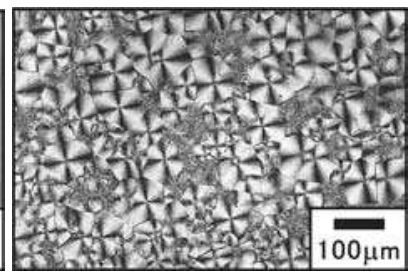

(b) $100^{\circ} \mathrm{C}-3 \mathrm{~h}$

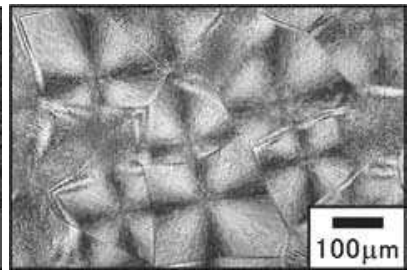

(c) $100^{\circ} \mathrm{C}-24 \mathrm{~h}$

Fig. 1. Polarized micrographs of microstructures of PLA.

It has been found that such microstructure dramatically affects the fracture behavior of PLA. As an example, the critical energy release rate, $G_{I C}$, measured at a quasi-static rate, 1 $\mathrm{mm} / \mathrm{min}$, and an impact rate, $1 \mathrm{~m} / \mathrm{s}$, of loading is shown in Fig.2. as a function of crystallinity. At the quasi-static rate, $G_{I C}$ slightly decreases with increase of crystallinity up to $11.6 \%$, and kept constant up to $48.3 \%$. Above $48.3 \%$, G IC rapidly decrease. On the other hand, at the impact rate, GIC tends to increase with increase of crystallinity. As a result, the static $G_{I C}$ is greater than the impact value up to $48.3 \%$, and above $48.3 \%$, on the contrary, the impact value becomes higher than the static value. This result suggests that the fracture mechanism at the static rate is different from that at the impact rate.

Fig. 3 shows polarized microphotographs of arrested cracks in the PLA specimens prepared under different annealing conditions, and tested under static and impact loading rates. For the amorphous specimen with the crystallinity, $X_{c}=2.7 \%$, under the static loading-rate (Fig.3(a)), extensive multiple crazes were generated in the crack-tip region, while only a few crazes were observed under the impact loading-rate (Fig.3(b)). This kind of craze formation in crack-tip region is usually observed in amorphous polymers such as polystyrene in which craze formation is dominant rather than shear plastic deformation (Botosis, 1987). Disappearance of multiple craze formation observed at the impact rate corresponds to the reduction of additional energy dissipation in the crack-tip region compared to the static case where multiple crazes are formed, and therefore results in the decrease of $G_{I C}$ as shown in Fig.2. On the contrary, for the highly crystallized specimen with $X_{c}=55.8 \%$ tested at the static rate (Fig.3(c)), a straight single crack without craze formation in the surroundings is observed. This type of crack growth usually corresponds to brittle fracture and lower $G_{I C}$ than the amorphous dominant samples in which crazes are generated in crack-tip region. At the impact rate (Fig.3(d)), the main crack tends to be distorted and branched. These behaviors may be related to the increase of $G_{I C}$ at the impact rate, although the detail of the mechanism is still unclear, and further study will be performed to elucidate such mechanism. 


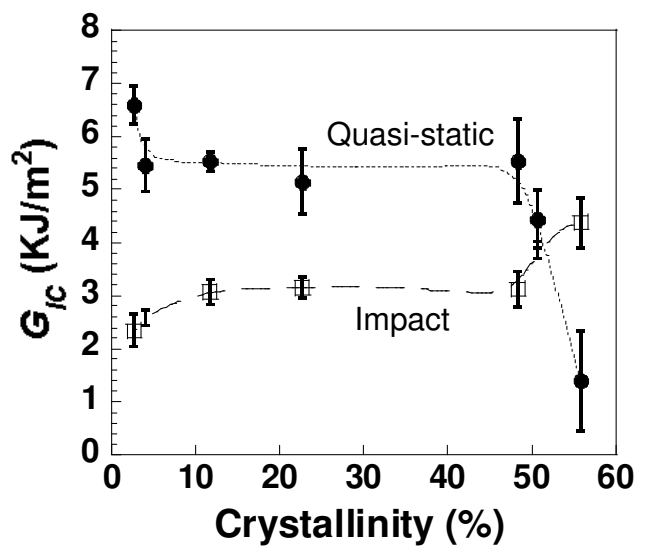

Fig. 2. Dependence of crystallinity on the critical energy release rate under a quasi-static and an impact loading conditions.

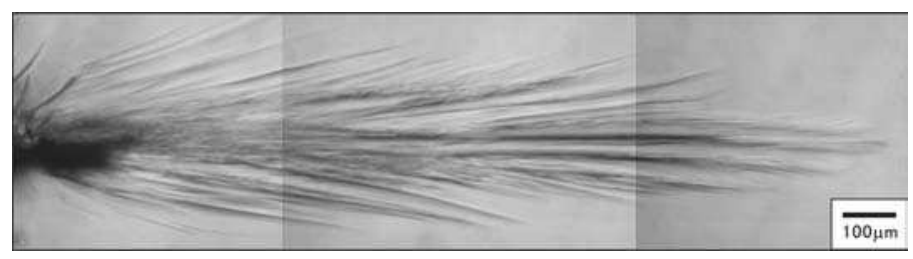

(a) $X_{c}=2.7 \%$, static

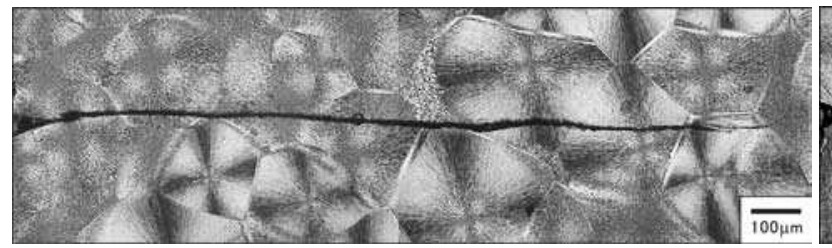

(c) $X_{c}=55.8 \%$, static

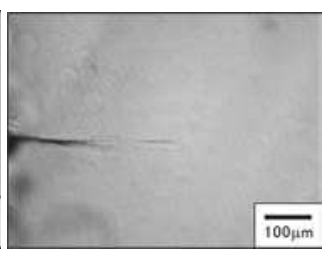

(b) $X_{c}=2.7 \%$, impact

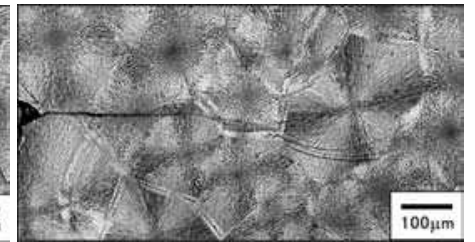

(d) $X_{c}=55.8 \%$, impact

Fig. 3. Polarized micrographs of crack growth behavior.

Fig.4 shows FE-SEM micrographs of the fracture surfaces of the PLA samples. For the amorphous sample tested at the static rate, the fracture surface exhibits deep concavities and hackles due to multiple craze formation (Fig.4(a)). The fracture surfaces of the crystallized samples (Fig.4(c)) appears to be smoother than the amorphous one, corresponding to the decrease of the toughness values. The impact fracture surface of the amorphous sample (Fig.4(b)) is obviously smoother than the static one, corresponding to the decrease of $G_{I C}$. It is noted that drawing fibrils are also observed on the impact fracture surface, suggesting that effect of high strain-rate exists. Roughness of the impact fracture surface appears to increase with increase of crystallinity comparing the surfaces shown in Figs.4(b) and (d). For the impact surface of the highly crystallized sample (Fig.4(d)), relatively fine roughness exists suggesting the increase of $G_{I C}$ as crystallinity increases. 


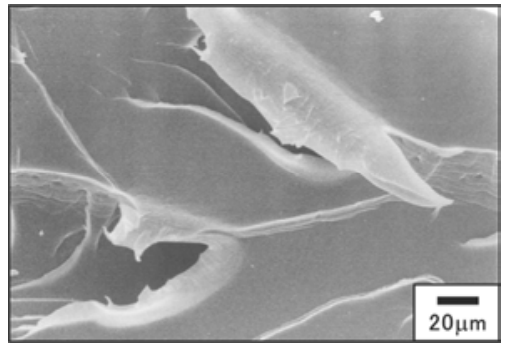

(a) $X_{c}=2.7 \%$, static

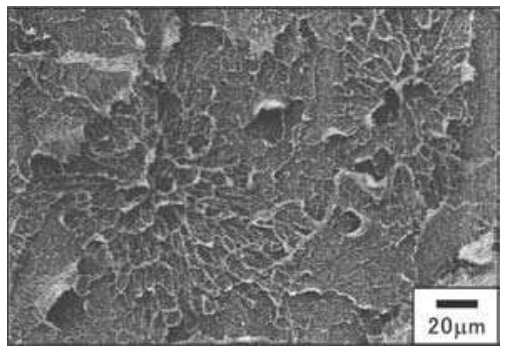

(c) $X_{c}=55.8 \%$, static

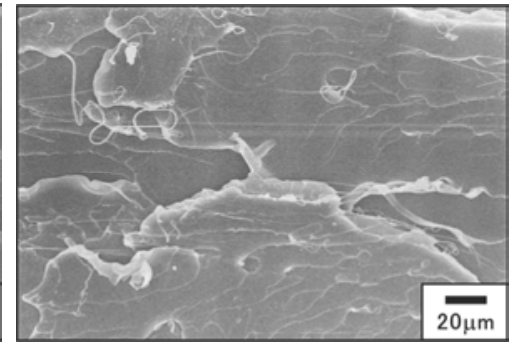

(b) $X_{c}=2.7 \%$, impact

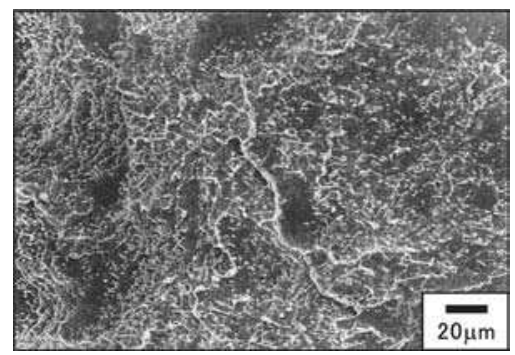

(d) $X_{c}=55.8 \%$, impact

Fig. 4. FE-SEM micrographs of fracture surfaces.

\subsection{Effect of unidirectional drawing process}

Drawing process is known to be an effective way to improve the mechanical properties of thermoplastics, and effects of drawing on tensile and fracture properties of thermoplastics such as polypropylene (Mohanraj et al., 2003a, 2003b; Uehara et al., 1996), poly(acrylonitrile) (Sawai et al., 1999; Yamane et al., 1997) and PLA (Todo, 2007) have been studied. PLA is usually draw-processed when it is used for bone fixation devices, and therefore, fundamental effect of drawing on its fracture behavior needs to be characterized. As an example, dependence of draw ratio on the critical J-integral at crack initiation, $J_{i n}$, is shown in Fig.5. In the fracture specimens, the initial notches were introduced in the direction perpendicular or parallel to the drawing direction. Therefore, the two different types of specimens are denoted as 'perpendicular' and 'parallel'. For the parallel, $J_{\text {in }}$ decreased with increase of draw ratio, and $J_{\text {in }}$ for draw ratio of 2.5 became about one fifth of the original. On the contrary, for the perpendicular, $J_{\text {in }}$ increased as draw ratio increased, and $J_{\text {in }}$ for draw ratio of 2.5 became five times greater than that of the original. Thus, greater energy is needed for crack propagation in the perpendicular than in the parallel. This is easily understood by considering the effect of drawing on the micromechanism of fracture. In draw-processed polymer, molecules are reoriented in the drawing direction. Therefore, energy dissipation during crack growth by elongation and scission of such oriented molecules is much greater in the perpendicular direction than in the parallel direction where such elongation and scission processes obviously decrease.

FE-SEM micrographs of fracture surfaces are shown in Fig. 6. The perpendicular with draw ratio 2.5 exhibited rougher surface with ductile deformation than the original (without drawing). It is interesting to note that crevices existed on the fracture surfaces that were thought to be cracks transversely propagated between the parallel fibrils reoriented in the 
drawing direction. It is thus thought that the ductile deformation due to elongation of the oriented molecules and the transverse crack formation are primary mechanisms of toughening in draw-processed PLA. On the other hand, the fracture surface of the parallel were much smoother than that of the original, corresponding to the lower $J_{\text {in }}$ value. $J_{\text {in }}$ is contributed by energy dissipation through not only creation of fracture surface but also development of process zone. Poralized micrographs of notch-tip regions of the original and the perpendicular are shown in Fig.7. In the original, multiple crazes forming a fan shape were observed. They were initiated from the initial notch-tip and propagated almost perpendicularly to the tensile direction. For the perpendicular with draw ratio 2.5 , crazes were much denser and the width of the damage region was much wider than the original. Transverse cracks generated in the drawing direction are observed, and these obviously correspond to the crevices observed on the fracture surfaces as shown in Fig.6(b). Larger damage region consisting of crazes and transverse cracks generated in crack-tip region indicates larger energy dissipation under crack initiation and propagation processes, and therefore, greater $J_{i n}$.

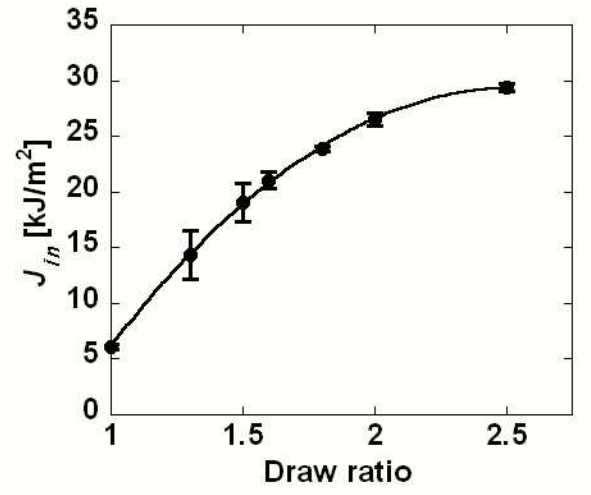

(a)Perpendicular direction

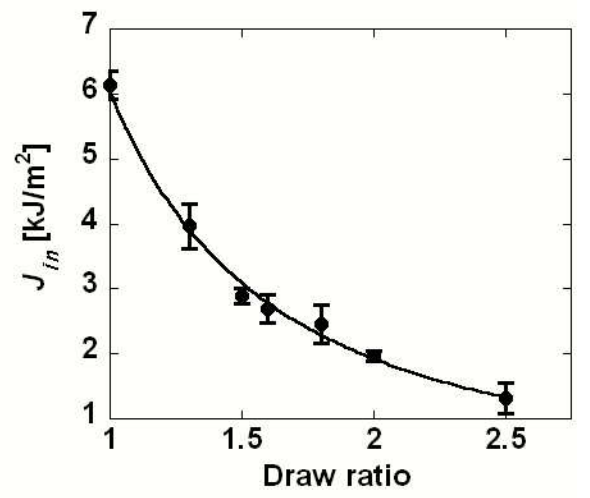

(b) Parallel direction

Fig. 5. Dependence of draw ratio on the critical J-integral at crack initation.

In summary, it was shown that the crystallization behavior greatly affects the fracture behavior of PLA. Microstructure of PLA can easily be changed through annealing process by changing temperature and heating time. The static fracture energy tends to decrease as crystallinity increases, while the impact fracture energy increases.

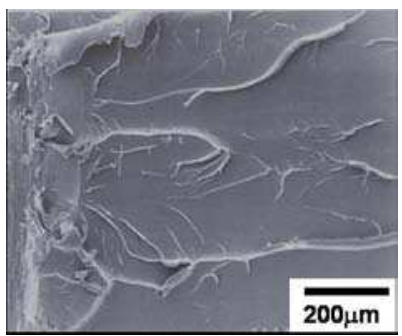

(a)Original

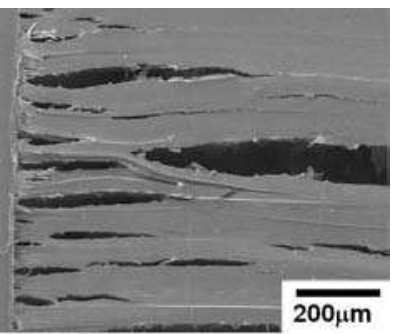

(b)Drawed, perpendicular

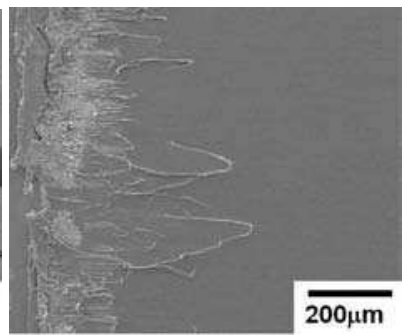

(c)Drawed, parallel

Fig. 6. FE-SEM micrographs of fracture surfaces (draw ratio=2.5). 


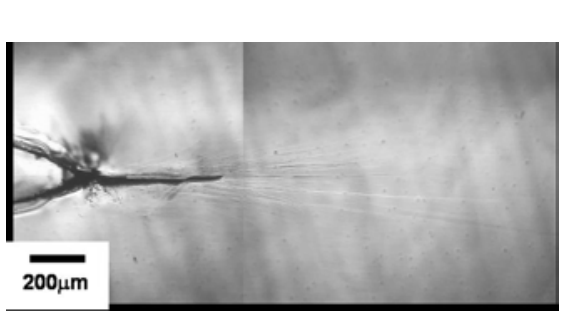

(a)Original

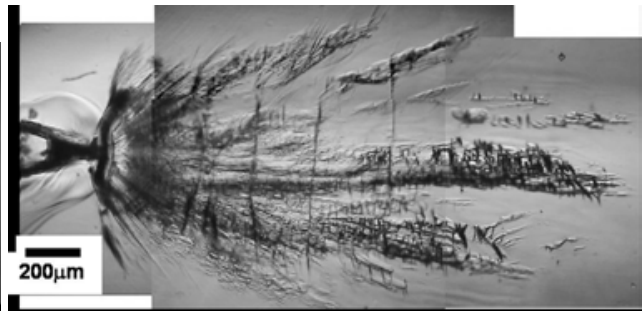

(b)draw ratio $=2.5$, perpendicular

Fig. 7. Poralized micrographs of damage zones.

\section{Fracture behavior of PLA/PCL blend}

Blending with ductile biodegradable polymers such as PCL (Broz, 2003; Dell'Erba, 2001; Chen, 2003; Todo, 2007; Tsuji, 1996, 1998, 2001, 2003), poly(butylene succinate-co- $\varepsilon^{-}$ caprolactone) (PBSC) (Vannaladsaysy, 2010) and poly (butylene succinate-co-L-lactate) (PBSL) (Shibata, 2006, 2007; Vannaladsaysy, 2009; Vilay, 2009) has extensively been investigated in order to improve the fracture energy of PLA. Amoung of them, PCL is known to be bioabsorbable and bioaabsorbable, therefore has been applied in medical fields. In this paragraph, the Mode I fracture behavior of PLA/PCL blend is discussed.

FE-SEM micrographs of the cryo-fracture surfaces of PLA/PCL blends are shown in Fig.8. Phase separations indicated as spherulites of PCL are clearly observed. It is obvious that the size of the PCL spherulites increases with increase of PCL content. It is also seen that voids are created as a result of removal of the dispersed PCL droplets. In general, a blend of immiscible polymers such as PLLA and PCL creates macro-phase separation of the two components due to difference of solubility parameter. This kind of phase separation dramatically affects the physical and mechanical properties of the blend (Dell'Erba et al., 2001; Maglio et al., 1999; Tsuji et al., 2003).

Dependence of PCL content on the critical energy release rate at crack initiation, $G_{i n}$ is shown in Fig.9. $G_{i n}$ increases with increase of PCL content up to $5 \mathrm{wt} \%$, and $G_{i n}$ becomes about 1.5 times greater than that of PLA. $G_{i n}$ slightly decreases as PCL content increases above $5 \mathrm{wt} \%$; however, $G_{\text {in }}$ values of the blends with 10 and $15 \mathrm{wt} \%$ of PCL are still higher than that of PLA.

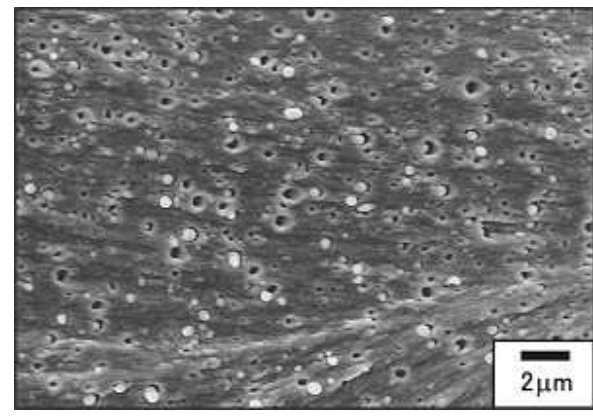

(a)PCL:5wt $\%$

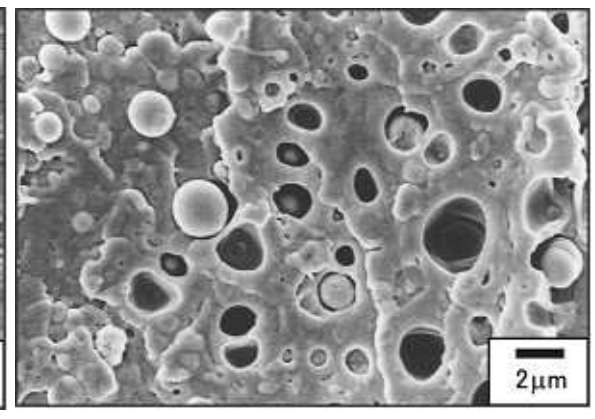

(b)PCL: $15 w t \%$

Fig. 8 Morphology of PLA/PCL blends 


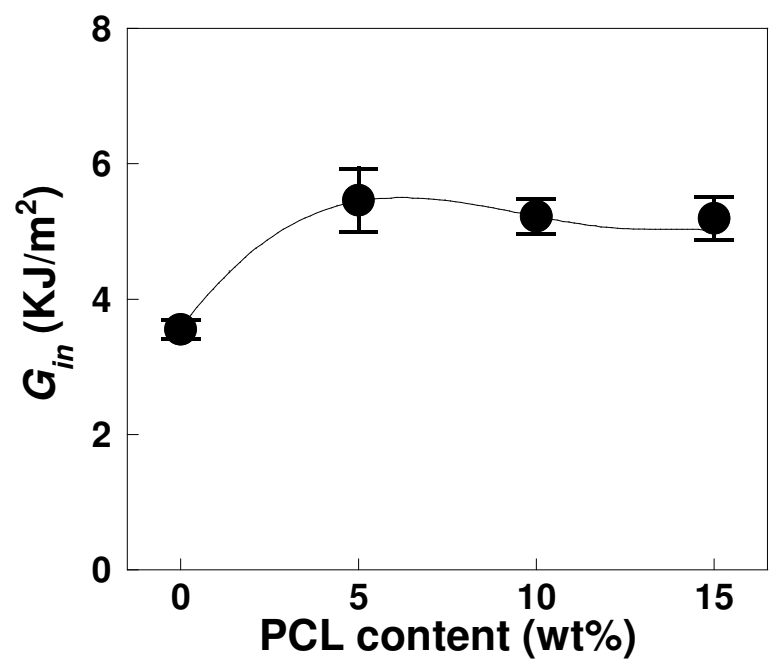

Fig. 9. Dependence of PCL content on the critical energy release rate at crack initiation.

Polarized micrograph of crack-tip region of PLA/PCL (PCL:15wt\%) is shown in Fig.10. Craze-like damages similar to neat PLA shown in Fig.7(a) are created in the crack-tip region, and the size of the damage zone is much larger than that of PLA. FE-SEM micrographs of surface on the crack-tip region are also shown in Fig.11. The right-hand figure is a micrograph of the craze-like damages at higher magnification. The micrograph clearly indicates a typical structure of craze, consisting of voids and fibrils. The spherulites of PCL are also seen. The extended fibrils of the matrix PLA were found to be much longer than those of the neat PLA, suggesting that the existence of the dispersed PCL spherulites in PLA tends to enhance ductile deformation of PLA fibrils. It is thus clear that the dispersed PCL droplets play an important role in the formation of the crazelike damages in PLA/PCL blend. FE-SEM micrograph of the fracture surface is shown in Fig.12. Increased ductile deformation of the matrix PLA with appearance of porous structures is clearly observed on the surface. These holes are thought to be created by removal of PCL droplets.

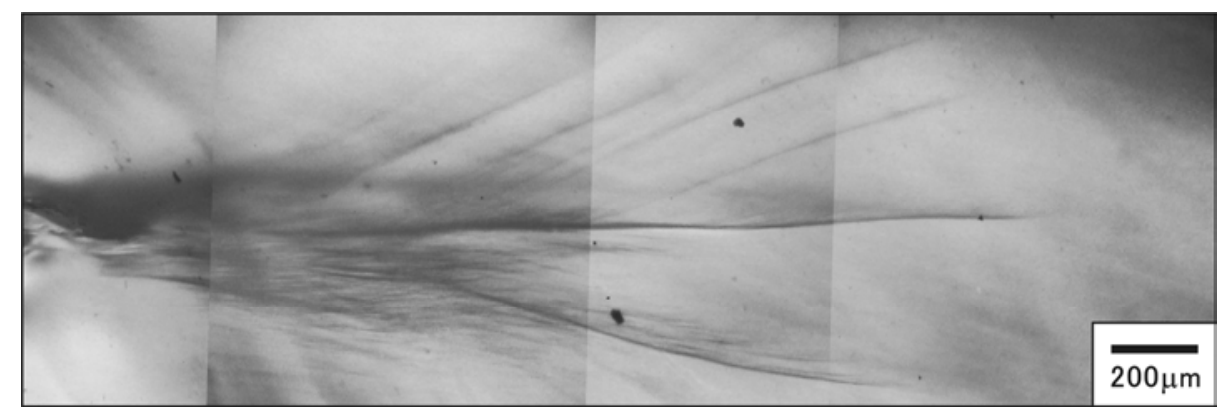

Fig. 10. Polarized micrograph of crack growth behavior in PLA/PCL. 


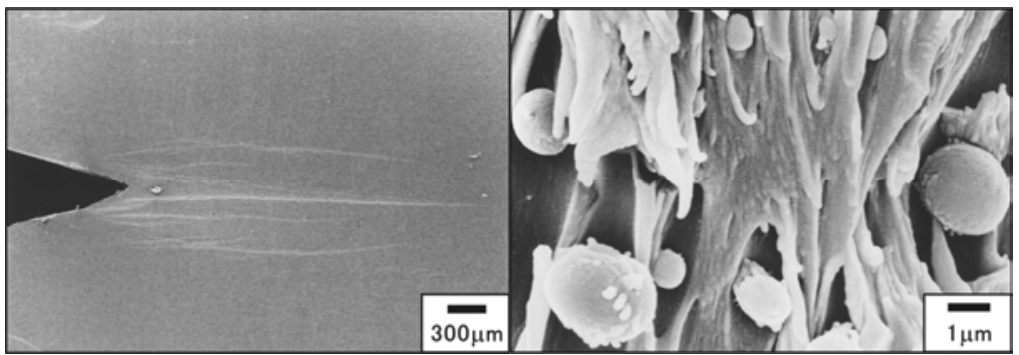

Fig. 11. FE-SEM micrographs of crack-tip region of PLA/PCL.

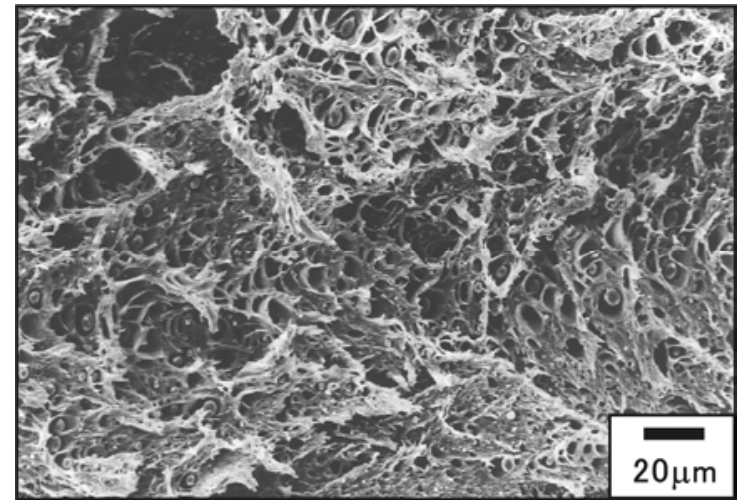

Fig. 12. FE-SEM micrograph of fracture surface of PLA/PCL.

In summary, it was shown that the fracture energy of PLA can be improved by blending with PCL with unchanged biocompatible and bioabsorbable characteristics. This improvement is considered to be achieved by stress relaxation and energy dissipation mechanisms such as extensive multiple craze formation of continuous phase and creation of extended fibril structures of dispersed phase. It is important to note that PLA/PCL exhibited phase separation due to incompatibility of two components, and created voids owing to removal of dispersed PCL phase. Those voids increased with increase of PCL content. PLA/PCL exhibited craze-like deformation of continuous phase similar to neat PLA during mode I fracture process, however, the size of the damage zone was much larger than the PLA, corresponding to the higher $G_{i n}$. PLA/PCL also showed creation of voids by PCL phase separation within the fracture process region, and these voids were likely to be extended at lower stress level, and therefore, decrease $G_{i n}$ due to local stress concentration.

\section{Toughness improvement of PLA/PCL blend}

\subsection{Effect of LTI}

As shown in the above section, blending with PCL successfully improved the fracture energy of brittle PLA. It was, however, also found that the immiscibility of PLA and PCL causes phase separation, and tends to lower the fracture energy especially when PCL content increases. It has recently been found that the addition of lysine tri-isocyanate (LTI) 
to PLA/PCL blends effectively improves their immiscibility (Takayama, 2006a, 2006b; Harada, 2007, 2008) and therefore the fracture energy (Takayama, 2006a, 2006b).

FE-SEM micrographs of cryo-fractured surfaces of PLA/PCL and PLA/PCL/LTI are shown in Fig.13. The content of PCL was $15 \mathrm{wt} \%$ in these materials. Spherical features appeared on the micrograph are thought to be PCL-rich phases. These micrographs clearly showed that the size of the PCL-rich phase dramatically decreases by LTI addition. It is thus presumed that LTI addition effectively improves the miscibility of PLA and PCL. This is thought to be related to the following chemical reaction, that is, the hydroxyl group of PLA and the isocyanate group of LTI creates urethane bond:

$$
\mathrm{HO}-\mathrm{R}^{\prime}+\mathrm{R}-\mathrm{N}=\mathrm{C}=\mathrm{O} \rightarrow \mathrm{R}-\mathrm{NHCOO}-\mathrm{R}^{\prime}
$$

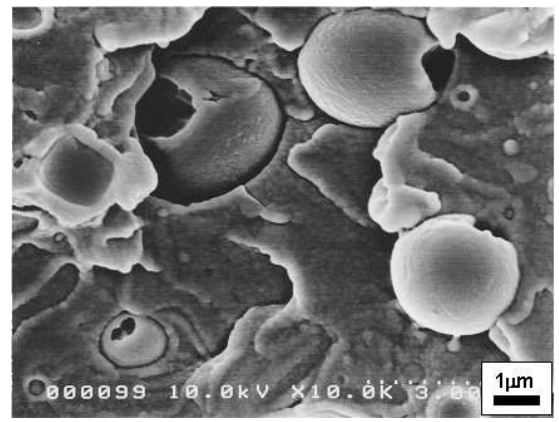

(a)PLA/PCL

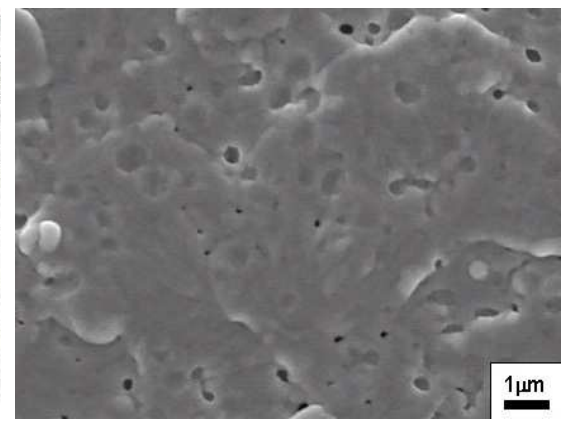

(b)PLA/PCL/LTI

Fig. 13. FE-SEM micrographs of cryo-fracture surfaces of PLA/PCL and PLA/PCL/LTI.

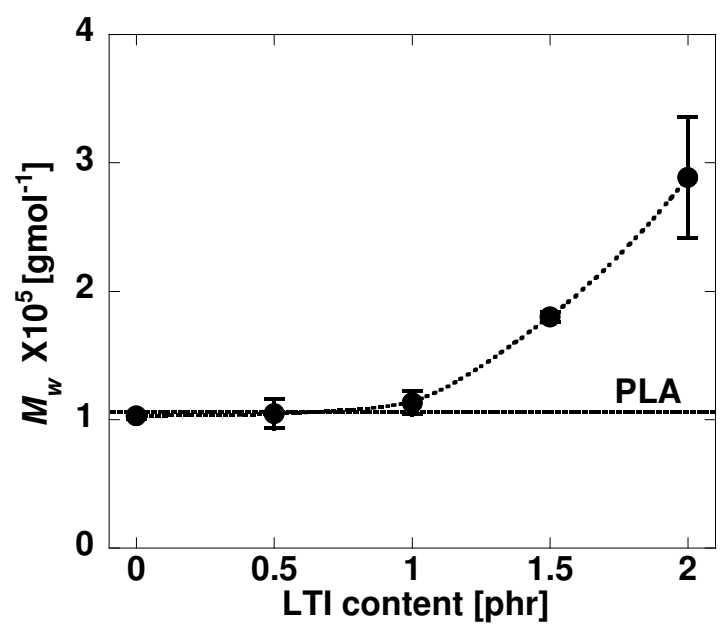

Fig. 14. Dependence of LTI content on the molecular weight.

Dependence of LTI content on the molecular weight, $M_{\mathrm{w}}$, is shown in Fig.14 - For comparison, $M_{\mathrm{w}}$ of neat PLA is also shown in the figure. $M_{\mathrm{w}}$ values of the blends tend to 
keep unchanged up to $1 \mathrm{phr}$ of LTI content, and then rapidly increase up to $2 \mathrm{phr}$, suggesting that the chemical reaction between the hydroxyl groups of PLA and PCL and the isocyanate groups of LTI was promoted by addition of LTI more than 1 phr. This microstructural change in molecular level due to LTI addition strongly support the macroscopic improvement of the fracture energy.

Dependence of LTI content on the crystallinity of PLA, $x_{c, \text { PLA}}$, is shownIn Fig.15. $\cdot x_{\mathrm{c}, \text { PLA }}$ of PLA/PCL and PLA/PCL/LTI with $0.5 \mathrm{phr}$ of LTI are higher than that of PLA. - It is considered that the crystallization of PLA in the blends was progressed actively more than in neat PLA. With increase of LTI content, $x_{\mathrm{c}, \text { PLA }}$ decreases rapidly at $1 \mathrm{phr}$ and this value is slightly lower than that of neat PLA. These results support that the phase separation between PLA and PCL is improved dramatically at 1 phr. It is presumed that the chemical reation between LTI and PLA/PCL during melt-mixing process results in the improvement of miscibility, and therefore the mobility of PLA and PCL molecules during solidification in cooling process is reduced, resulting in the reduction of crystallization.

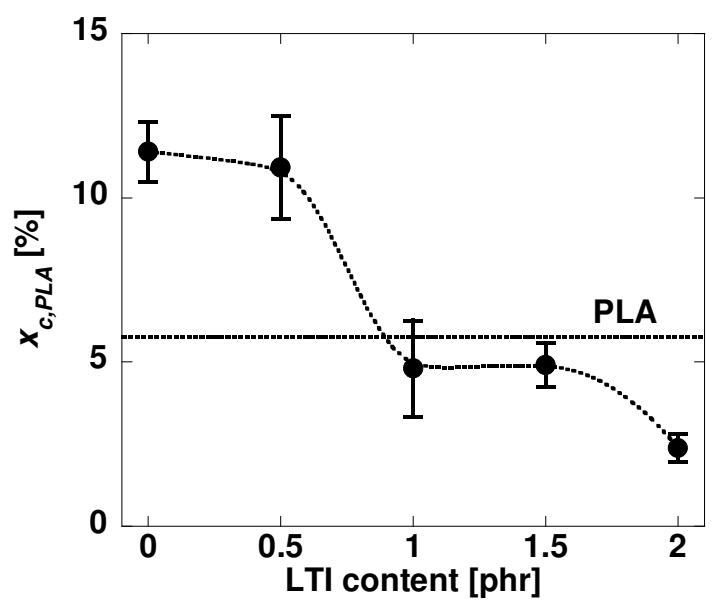

Fig. 15. Dependence of LTI content on crystallinity of PLA in PLA/PCL and PLA/PCL/LTI.

Dependence of LTI content on $J_{\text {in }}$ is shown in Fig. 16. It is seen that $J_{\text {in }}$ of PLA/PCL is a little larger than that of PLA, indicating the effectiveness of PCL blend on $J_{\text {in }}$ is very low. $J_{\text {in }}$ of PLA/PCL is effectively improved by LTI addition, and $J_{\text {in }}$ increases with increase of LTI content up to $1.5 \mathrm{phr}$. There is no difference of $J_{\text {in }}$ between 2 phr and 1 phr of LTI addition, suggesting that the improvement of $J_{\text {in }}$ is saturated with about 1.5 phr of LTI.

Poralized micrographs of crack growth behaviors in PLA/PCL/LTI are shown in Fig.17. In PLA/PCL/LTI with $0.5 \mathrm{phr}$ of LTI, craze-like features are still seen in the crack-tip region as also seen in neat PLA (Fig.7(a)) and PLA/PCL blend (Fig.10). The number of the craze-lines is obviously decreased due to LTI addition. With higher content of LTI, such craze-like feature is no longer generated, and instead, the crack-tip region is plastically deformed, very similar to the crack-tip deformation in ductile plastics and metal. It is known that this kind of plastic deformation dissipates more energy than the craze-like damage, resulting in the greater fracture energy. It is therefore thought that LTI addition to PLA/PCL dramatically changes the crack-tip deformation mechanism; as a result, $J_{\text {in }}$ is greatly improved. 


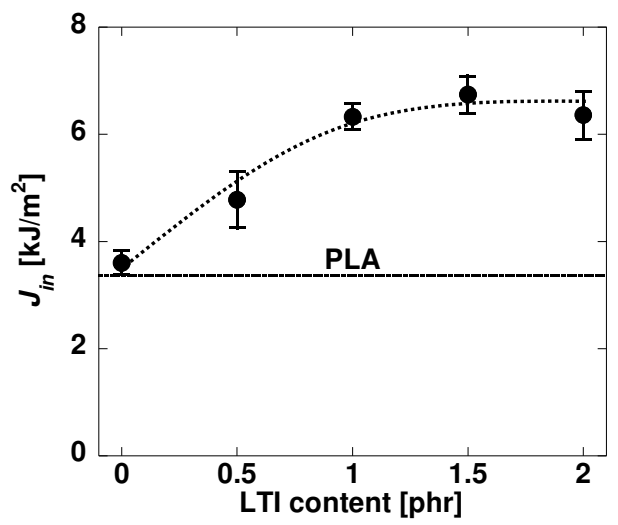

Fig. 16. Dependent of LTI content on the fracture energy, $J_{\text {in }}$.

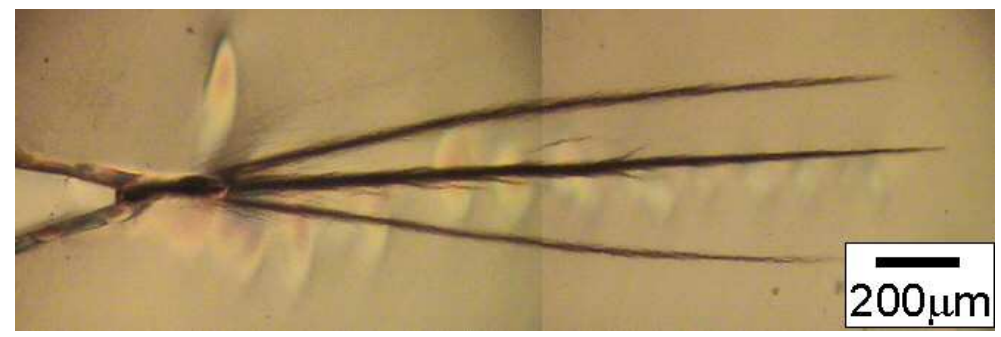

(a)LTI: $0.5 \mathrm{phr}$

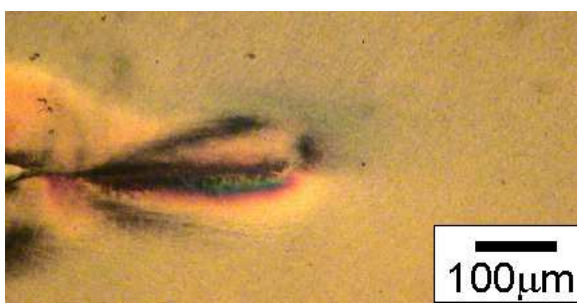

(b)LTI:1 phr

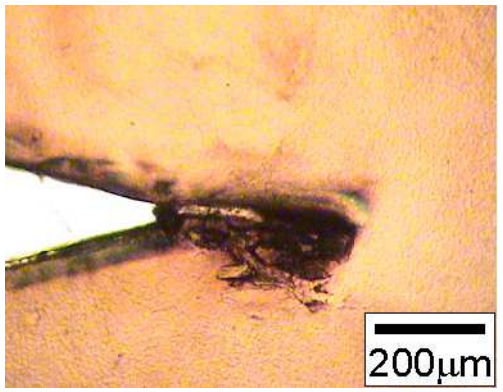

(c)LTI:2phr

Fig. 17. Poralized micrographs of crack growth behaviors in PLA/PCL/LTI.

FE-SEM micrographs of fracture surfaces of PLA, PLA/PCL and PLA/PCL/LTI are shown in Fig. 18. The fracture surface of PLA is very smooth, corresponding to a brittle fracture behavior with low fracture energy. The surface roughness increases with the existence of elongated PCL and cavities by PCL blending. These cavities are thought to be created by debonding of the PCL-rich phases from the surrounding PLA matrix phase and usually cause local stress concentration in the surrounding regions. Thus, this kind of cavitation tends to lower the fracture energy because of the local stress concentration, and 
compensates to the increase of fracture energy due to the ductile deformation of PCL. This is the reason for the slight improvement of $J_{\text {in }}$ in PLA/PCL shown in Fig. 16. It is clearly seen from Fig. 18(c) that cavities do not exist on the fracture surface of PLA/PCL/LTI, indicating that the miscibility of PLA and PCL improves due to LTI addition. In addition, elongated structures are more on PLA/PCL/LTI than PLA/PCL. Thus, extensive ductile deformation associated with disappearance of cavitation is the primary mechanism of the dramatic improvement of $J_{i n}$.

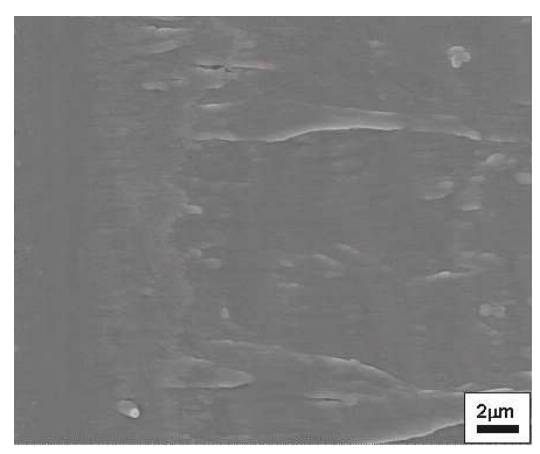

(a)PLA

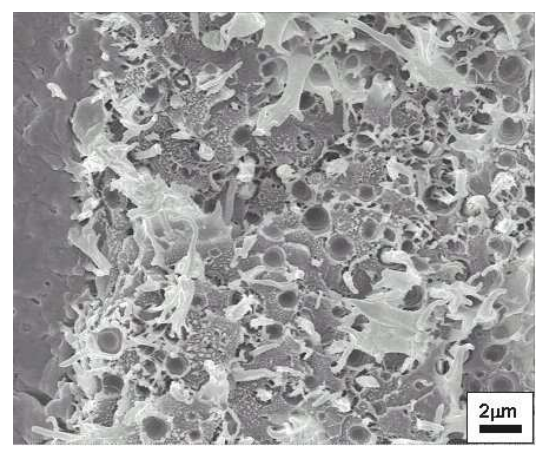

(b)PLA/PCL

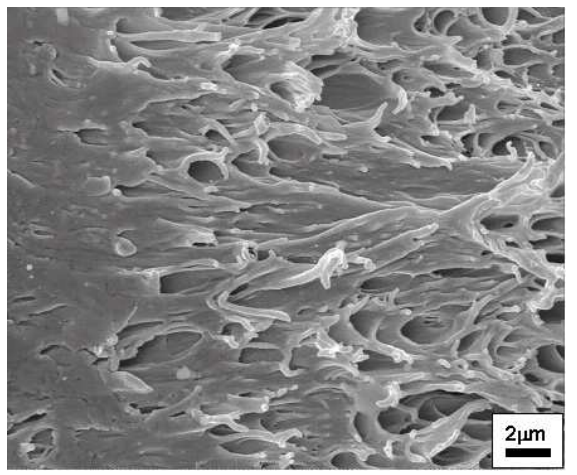

(c)PLA/PCL/LTI

Fig. 18. FE-SEM microgprahs of fracture surfaces of PLA, PLA/PCL and PLA/PCL/LTI.

In summary, the miscibility between PLA and PCL is dramatically improved by introducing LTI as an additive. The increase of molecular weight and the decrease of crystallinity with increase of LTI content clearly indicate that crosslinks are generated by urethane bonds in which the hydroxyl groups at the ends of PLA and PCL molecules react with the isocyanate groups of LTI during molding process. Such microstructural modification results in the dramatic improvement of the macroscopic fracture property, $J_{i n}$.

\subsection{Effect of annealing process on PLA/PCL/LTI}

As described in the previous section, the immiscibility of PLA/PCL can be improved by adding LTI as a compatibilizer, and as a result, the fracture energy of PLA/PCL is 
effectively improved. However, blending of ductile PCL with PLA degrades another mechanical properties such as strength and elastic modulus of the base polymer PLA. Recently, Tsuji et al. found that the mechanical properties such as elastic modulus and tensile strength of PLA could be improved by annealing (Tsuji et al., 1995). It is thus expected that annealing process may also affect on the mechanical properties of PLA/PCL/LTI blend.

FE-SEM micrographs of cryo-fracture surfaces of quenched and annealed PLA/PCL and PLA/PCL/LTI are shown in Fig.19. Both the quenched and the annealed PLA/PCL show spherical structures of PCL. It is obviously seen that PCL spherulites in PLA/PCL/LTI are much smaller than those in PLA/PCL. The annealed blends exhibit rougher surfaces with spherical structures than the quenched samples. These spherical structures are thought to be the spherulites of PLA generated by crystallization during annealing process.

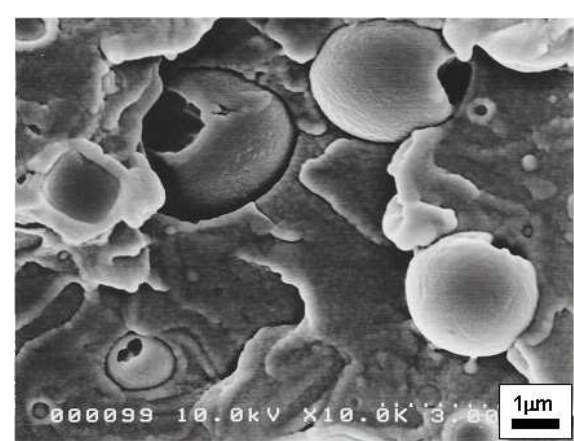

(a) Quenched PLA/PCL

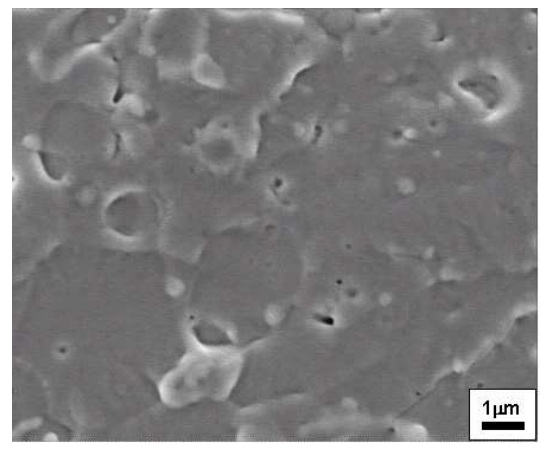

(c) Quenched PLA/PCL/LTI

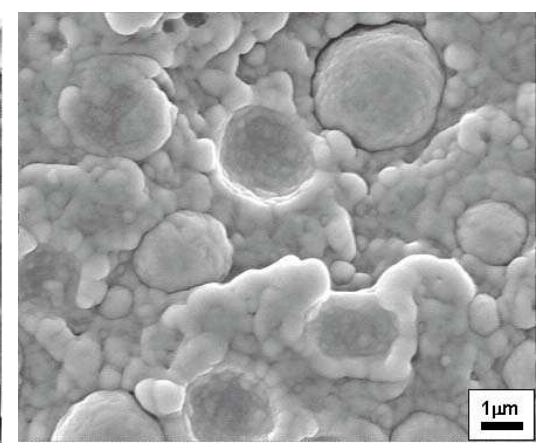

(b) Annealed PLA/PCL

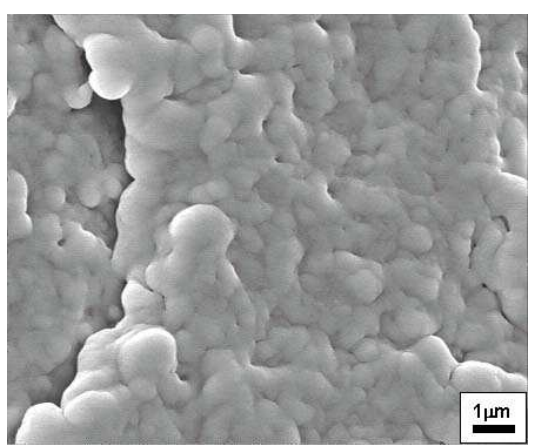

(d) Annealed PLA/PCL/LTI

Fig. 19. FE-SEM micrographs of microstructures of PLA/PCL and PLA/PCL/LTI.

Effects of annealing on the elastic modulus, $E$, and the strength, $\sigma_{f}$, under three-point bending condition are shown in Fig.20. Both $E$ and $\sigma_{f}$ increase due to annealing. Effects of annealing on the crystallinity, $x_{c, P L A}$, and the molecular weight, $M_{w}$, are also shown in Table 1. It is clearly seen that $x_{c, P L A}$ dramatically increases due to annealing. Thus, increasing $x_{c, P L A}$ is likely to strengthen the structure of the polymer, resulting in the increase of $E$ and $\sigma_{f} . M_{w}$ of PLA/PCL increases slightly due to LTI, suggesting that LTI is thought to generate 
additional polymerization with hydroxyl and carboxyl groups lying in the ends of PLA or PCL molecules. This polymerization results in the improvement of miscibility of PLA and PCL as shown in Fig.19(c). On the other hand, $M_{w}$ of PLA/PCL decreases slightly due to annealing, indicating progression of thermal degradation in this blend. On the contrary, $M_{w}$ of PLA/PCL/LTI slightly increases, suggesting that additional polymerization take place during annealing process.

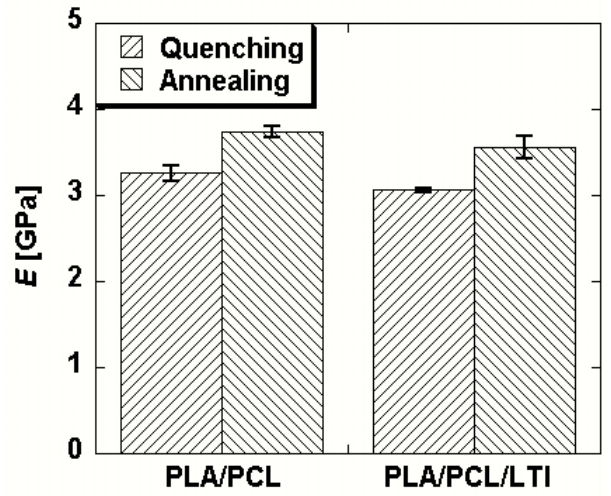

(a)Elastic modulus

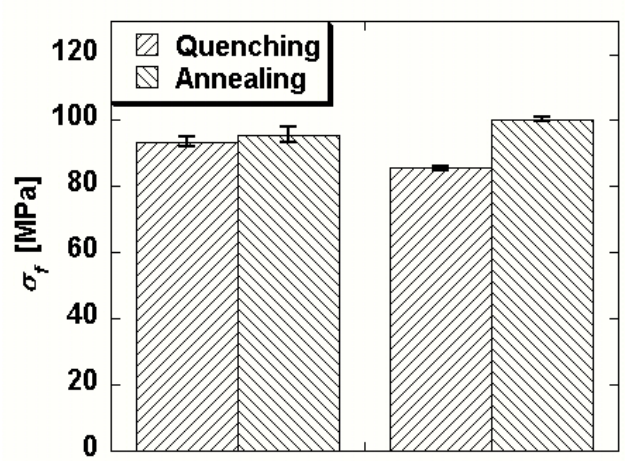

PLA/PCL
PLA/PCL/LTI

(b)Strength

Fig. 20. Effects of annealing on bending mechanical properties.

\begin{tabular}{lcc}
\hline Blend & $X_{c, \text { PLA }}(\%)$ & $M_{w}(\mathrm{~g} / \mathrm{mol})$ \\
\hline Quenched PLA/PCL & 11.4 & $1.03 \times 10^{5}$ \\
Annealed PLA/PCL & 45.6 & $9.08 \times 10^{4}$ \\
Quenched PLA/PCL/LTI & 4.8 & $1.13 \times 10^{5}$ \\
Annealed PLA/PCL/LTI & 36.6 & $1.52 \times 10^{5}$ \\
\hline
\end{tabular}

Table 1. Effects of annealing on the crystallinity and molecular weight.

Effects of annealing on the critical J-integral at crack initiation, $J_{i n}$, are shown in Fig.21. It is clearly seen that $J_{\text {in }}$ of PLA/PCL/LTI effectively increases due to annealing; on the contrary, PLA/PCL exhibites decrease of $J_{\text {in }}$.

FE-SEM micrographs of the fracture surfaces of the mode I fracture specimens are shown in Fig.22. By comparing Figs.22(a) and (b), it is clearly seen that ductile deformation of spherical PCL phase is suppressed by annealing. Cavities are also observed on the surface of PLA/PCL, as a result of removal of the spherical PCL phases. FE-SEM micrographs at higher magnification show that elongated structures of the spherical PCL phases are observed in the quenched PLA/PCL, while ruptured PLA fibrils and undeformed PCL spherulites are observed in the annealed PLA/PCL. It is also interesting to see in Fig.22(a) that some PCL fibrils are penetrated into the PLA phase and seem to be entangled with PLA fibrils. It is thought that the PLA phase creates a firm structure due to crystallization by annealing and therefore, entangled PCL fibrils with PLA fibrils are firmly trapped in the PLA phase. The PCL spherulites are thus surrounded by such firm crystallized PLA phase with entanglement of PLA and PCL fibrils, resulting in the rupture of the PCL fibrils and the 
suppression of ductile deformation of the PCL spherulites. This is considered to be the primary reason for the degradation of $J_{\text {in }}$ as shown in Fig.21.

It is clearly seen from Figs.22(c) and (d) that in the PLA/PCL/LTI blends, cavity formation is totally suppressed and as a result, ductile deformation is expanded due to the improved miscibility of PLA and PCL by LTI addition. This implies that the miscibility of PLA and PCL is improved by crosslinking of PLA and PCL macromolecules induced by the chemical reaction between the hydroxyl group of PLA and PCL and the isocyanate group of LTI. FESEM micrographs at higher magnification show that for both the quenched and annealed PLA/PCL/LTI blends, entangled fibril structures of PLA and PCL are observed. It is thus considered that this kind of structural transformation due to polymerization by LTI blending results in strengthening the structure of the PLA/PCL blends. The microstructure of PLA/PCL/LTI is thought to be further strengthened due to crystallization of PLA by annealing, resulting in the dramatic improvement of the mode I fracture energy $J_{\text {in }}$ as shown in Fig.22.

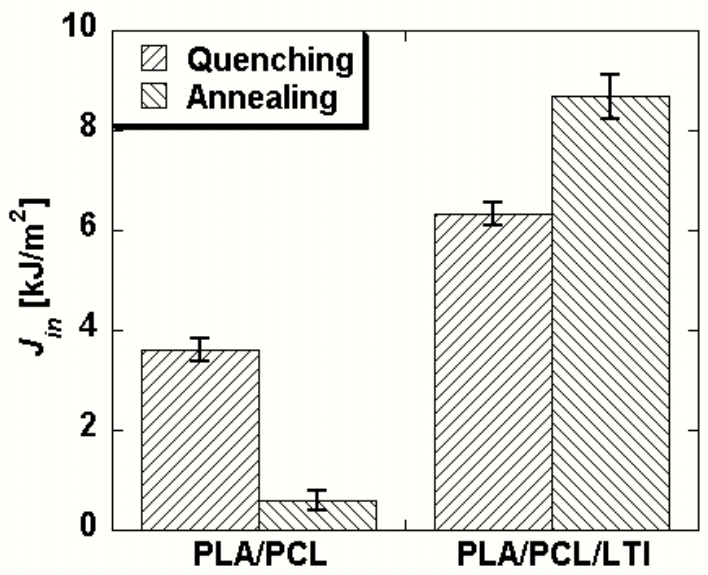

Fig. 21. Effects of annealing on the critical J-integral at crack intiation, $J_{i n}$.
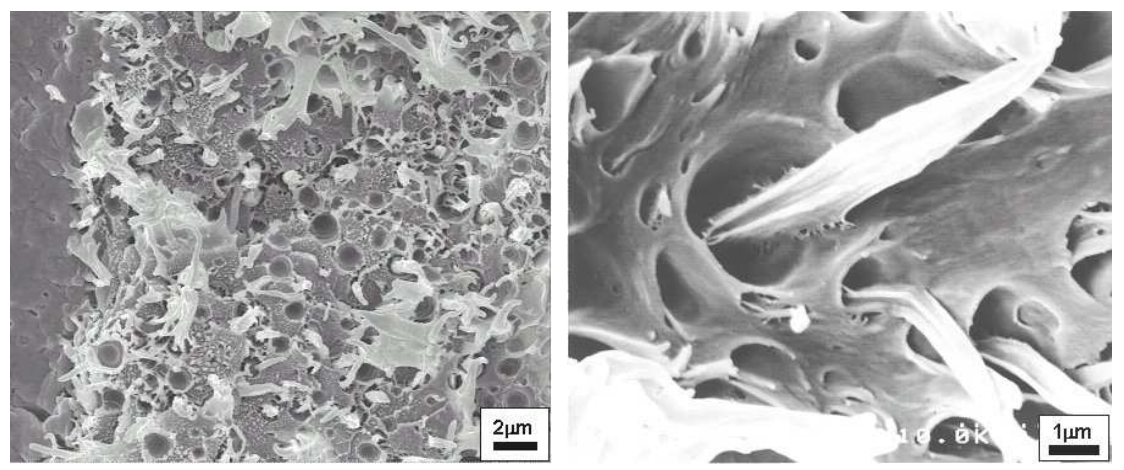

(a) Quenched PLA/PCL 

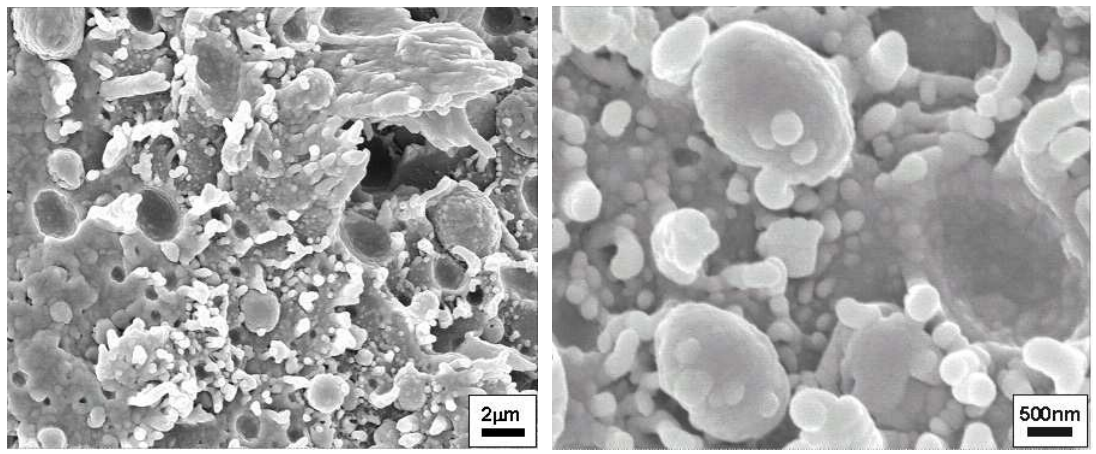

(b) Annealed PLA/PCL
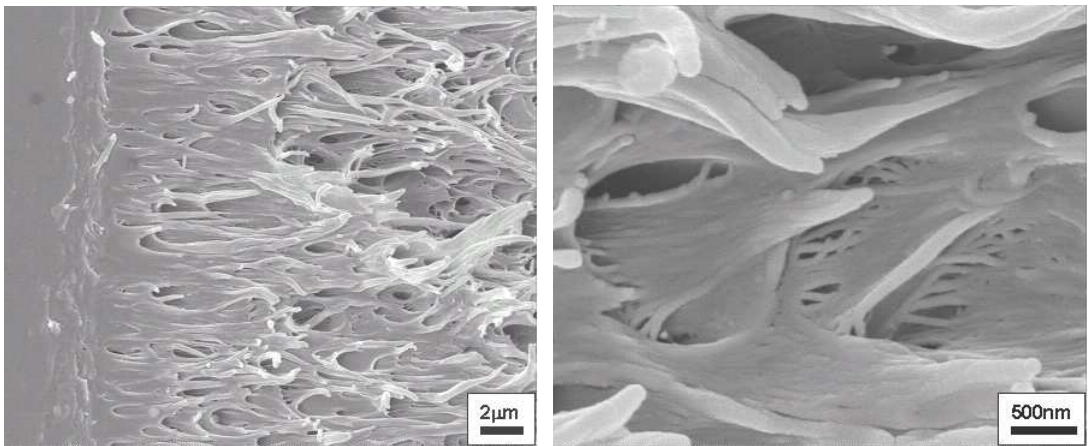

(c) Quenched PLA/PCL/LTI
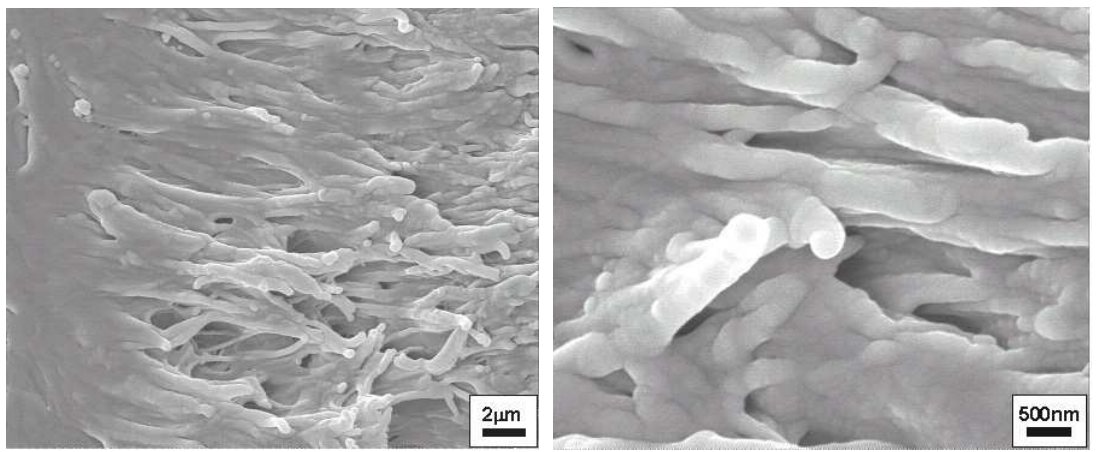

(d) Annealed PLA/PCL/LTI

Fig. 22. FE-SEM micrographs of fracture surfaces of quenched and annealed samples.

In summary, the bending modulus and strength of both PLA/PCL and PLA/PCL/LTI are effectively improved by annealing. Crystallization of the PLA phase by annealing is thought to strengthen the structure of the PLA/PCL blend, resulting in increase of these properties. The mode I fracture energy of PLA/PCL significantly decreases by annealing mainly owing to embrittlement of the PLA phase. For the case of PLA/PCL/LTI, the structural transformation due to polymerization by LTI addition and crystallization by annealing 
strengthen the microstructure, resulting in the dramatic improvement of the mode I fracture energy.

\section{Conclusion}

In this chapter, the fundamental fracture characteristics of bioabsorbable PLA were firstly discussed, and then as examples of toughening, effects of unidirectional drawing and blending with PCL on the fracture behavior were presented. Finally, microstructural modification for PLA/PCL blends using LTI additive was discussed. Thermal processes have great influences on the microstructure and the mechanical properties of PLA mainly due to crystallization behaviour during the heating process. Highly crystallized PLA tends to exhibit very brittle fracture behavior with low fracture energy. Amorphous PLA can generate multiple crazes at crack-tip region to dissipate more energy during fracture process than crystallized materials in which craze formation is suppressed. Drawing process can arrange molecules in one direction so that the fracture resistance in the perpendicular to the drawing direction is greatly improved, while the resistance in the drawing direction tends to degrade. Another effective way to improve the fracture energy is blending with ductile polymer such as PCL. PLA/PCL blends show higher fracture energy with extensive damage formation in crack-tip regions than neat PLA; however, the immiscibility of PLA and PCL results in phase separation morphology in which spherulites of PCL are dispersed in PLA matrix. Such morphological problem can effectively be improved by using LTI as an additive. The phase separation is almost disappeared and the fracture energy is greatly improved. The fracture micromechanism is changed from multiple craze-like damage formation to plastic deformation in crack-tip region. Furthermore, the mechanical properties including elastic modulus, strength and fracture energy of PLA/PCL/LTI blends can effectively be improved by introducing annealing process, although such process tends to degrade the fracture energy of PLA/PCL blends.

\section{References}

Botsis, J., Chudnovsky, A., Moet, A. (1987). Fatigue crack layer propagation in polystyrene. 1. experimental observations. International Journal of Fracture, Vol.33, No.4, pp.263276.

Broz, M.E., VanderHart, D.L., Washburn, N.R. (2003). Structure and mechanical properties of poly(DmL-lactic acid)/poly(e-caprolactone) blends. Biomaterials, Vol.24, pp.41814190.

Chen, C.C., Chueh, J.Y., Tseng, H., Huang, H.M., Lee, S.Y. (2003). Preparation and characterization of PLA plymeric blends. Biomaterials, Vol.24, pp.1167-1173.

Dell'Erba, R., Groeninckx, G., Maglio, G., Malinconico, M., Migliozzi, A. (2001). Immiscible polymer blends of semicrystalline biocompatible components: Thermal properties and phase morphology analysis of PLLA/PCL blends. Polymer, Vol.42, pp.78317840 .

Harada, M., Ohya, T., Iida, K., Hayashi, H., Hirano, K., Fukuda, H. (2007). Increased impact strength of biodegradable poly(lactic acid)/poly(butylene succinate) blend composites by using isocyanate as a reactive processing agent, Journal of Applied Polymer Science, Vol.106, No.3, pp.1813-11820. 
Harada, M., Iida, K., Okamoto, K., Hayashi, H., Hirano, K. (2008). Reactive compatibilization of biodegradable poly(lactic acid)/poly(epsilon-caprolactone) blends with reactive processing agents, Polymer Engineering and Science, Vol.48, No.7, pp.1359-1368.

Higashi, S., Tamamoto, T., Nakamura, T., Ikada, Y., Hyon, S.H., Jamshidi. K. (1986). Polymer-hydroxyapatite composites for biodegradable bone fillers. Biomaterials, Vol.7, pp.183-187.

Ikada, Y., Shikinami, Y., Hara, Y., Tagawa, M., Fukuda, E. (1996). Enhancement of bone formation by drawn poly(L-lactide). Journal of Biomedical Materials Research, Vol. 30, pp.553-558.

Maglio, G., Migliozzi, A., Palumbo, R., Immizi, B., Volpe, M.G. (1999). Compatibilized poly(E-caprolactone)/poly(L-lactide) blends for biomedical uses. Macromolecules Rapid Communication, Vol.20, pp.236-238.

Middleton, J.C., Tipton, A.J. (2000). Synthetic biodegradable polymers as orthopedic devices. Biomaterials, Vol.21, pp.2335-2346.

Mohanraj, J., Chapleau, N., Ajji, A., Duckett, R.A., Ward, I.M. (2003a). Fracture behavior of die-drawn toughened polypropylenes. Journal of Applied Polymer Science, Vol.88, pp.1336-1345.

Mohanraj, J., Chapleau, N., Ajji, A., Duckett, R.A., Ward, I.M. (2003b). Production, properties and impact toughness of die-drawn toughened polypropylenes. Polymer Engineering Science, Vol.43, No.6, pp.1317-1335.

Mohanty, A.K., Misra, M., Hinrichsen, G. (2000). Biofibres, biodegradable polymers and biocomposites:An overview. Macromolecular Materrials and Engineering, Vol.276/277, pp.1-24.

Park, S.D., Todo, M., Arakawa, K. (2004). Effect of annealing on the fracture toughness of poly(lactic acid), Journal of Materials Science, Vol.39, pp.1113-1116.

Park, S.D., Todo, M., Arakawa, K. (2005). Effects of isothermal crystallization on fracture toughness and crack growth behavior of poly(lactic acid), Journal of Materials Science, Vol.40, pp.1055-1058.

Park, S.D., Todo, M., Arakawa, K., Koganemaru, M. (2006). Effect of crystallinity and loading-rate on mode I fracture behavior of poly(lactic acid). Polymer, Vol.47, pp.1357-1363.

Sawai, D., Yamane, A., Kameda, T., Kanamoto, T., Ito, M., Yamazaki, M., Hisatani, K. (1999). Uniaxial drawing of isotactic poly(acrylonitrile): development of oriented structure and tensile proeprties. Macromolecules, Vol.32, No.17, pp.5622-5630.

Shibata, M., Teramoto, N., Inoue Y. (2006). Mechanical properties, morphologies, and crystallization behavior of blends of poly(L-lactide) with poly(butylene succinateco-L-lactate) aaand poly(butylene succinate). Polymer, Vol.47, pp.3557-3564.

Shibata, M., Teramoto, N., Inoue Y. (2007). Mechanical properties, morphologies, and crystallization behavior of plasticized poly(L-lactide)/ poly(butylene succinate-coL-lactate) blends. Polymer, Vol.48, pp.2768-2777.

Takayama, T., Todo, M. (2006). Improvement of impact fracture properties of PLA/PCL polymer blend due to LTI addition. Journal of Materials Science, Vol.41, No.15, pp.4989-4992.

Takayama, T., Todo, M., Tsuji, H., Arakawa, K. (2006). Effect of LTI content on impact fracture property of PLA/PCL/LTI polymer blends. Journal of Materials Science, Vol.41, No.19, pp.6501-6504. 
Takayama, T., Todo, M., Tsuji, H. (2011). Effect of annealing on the mechanical properties of PLA/PCL and PLA/PCL/LTI polymer blends. Journal of the Mechanical Behavior of Biomedical Materials, Vol.4, pp.255-260.

Todo, M., Shinohara , N., Arakawa, K. (2002). Effects of crystallization and loading-rate on the mode I fracture toughness of biodegradable poly(lactic acid). Journal of Materials Science Letters, Vol.21, pp.1203-1206.

Todo, M., Kagawa, T., Takenoshita, Y., Myoui, A. (2008). Effect of press processing on fracture behavior of HA/PLLA biocomposite material. Journal of Solid Mechanics and Materials Engineering, Vol.2, No.1, pp.1-7.

Todo, M., Takayama, T. (2007). Improvement of mechanical properties of poly(l-lactic acid) by blending of lysine triisocyanate. Journal of Materials Science, Vol.42, pp.4721-4724.

Todo, M., Takayama, T., Tsuji, H., Arakawa, K. (2007a). Effect of LTI blending on fracture proeprties of PLA/PCL polymer blend. Journal of Solid Mechanics and Materials Engineering, Vol.1, No.9, pp.1157-1164.

Todo, M., Park, S.D., Takayama, T., Arakawa, K. (2007b). Fracture micromechanisms of bioabsorbable PLLA/PCL polymer blends. Engineering Fracture Mechanics, Vol.74, pp. 1872-1883.

Todo, M. (2007). Effect of unidirectional drawing process on fracture behavior of poly(Llactide). Journal of Materials Science, Vol.42, No.4, pp.1393-1396.

Tsuji, H., Ikada, Y. (1995). Properties and morphologies of poly (L-lactide): 1. Annealing condition effects on properties and morphologies of poly (L-lactide). Polymer, Vol.36, pp.2709-2716.

Tsuji, H., Ikada, Y. (1996). Blends of aliphatic polyesters. I. Physical proeprties and morphologies of solution-cast blends from poly(DL-lactide) and poly( $\varepsilon$ caprolactone). Journal of Apllied Polymer Science, Vol.60, pp.2367-2375.

Tsuji, H., Ikada, Y. (1997). Blends of aliphatic polyesters. II. Hydrolysis of solution-cast blends from poly(L-lactide) and poly( $\varepsilon$-caprolactone) in phosphate-buffered solution. Journal of Apllied Polymer Science, Vol.67, pp.405-415.

Tsuji, H., Ishizuka, T. (2001). Porous biodegradable polyesters, 3 Preparation of porous poly( $\varepsilon$-caprolactone) films from blends by selective enzymatic removal of poly(Llactide). Macromolecular Bioscience, Vol.1, No.2, pp.59-65.

Tsuji, H., Yamada, T., Suzuki, M., Itsuno, S. (2003). Blends of aliphatic polyesters. part 7. effects of poly(L-lactide-co- $\varepsilon$-caprolactone) on morphology, structure, crystallization, and physical properties of blends of poly(L-lactide) and poly( $\varepsilon$ caprolactone). Polymer Journal, Vol.52, pp.269-275.

Uehara, H., Yamazaki, Y., Kanamoto, T. (1996). Tensile properties of highly syndiotactic polypropylene. Polymer, Vol.37, No.1, pp.57-64.

Vannaladsaysy, V., Todo, M., Takayama, T., Jaafar, M., Zulkifli, A., Pasomsouk, K. (2009). Effect of lysine triisocyanate on the mode I fracture behavior of polymer blend of poly(L-lactic acid) and poly(butylene succinate-co-L-lactide). Journal of Materials Science, Vol.44, No.11, pp.3006-3009.

Vannaladsaysy,V., Todo, M., Jaafar, M., Ahmad, Z. (2010). Characterization of microstructure and mechanical properties of biodegradable polymer blends of poly(L-lactic acid) and poly(butylene succinate-co- $\varepsilon$-caprolactone) with lysine triisocyanate. Polymer Engineering and Science, Vol.50, No.7, pp.1485-1491. 
Vilay, V., Mariatti, M., Ahmad, Z., Pasomsouk, K., Todo, M. (2010). Improvement of microstructures and properties of biodegradable PLLA and PCL blends compatibilized with a triblock copolymer. Materials Science and Engineering A, Vol.527, No.26, pp.6930 - 6937.

Vilay, V., Mariatti, M., Ahmad, Z., Pasomsouk, K., Todo, M. (2009). Characterization of the mechanical and thermal properties and morphological behavior of biodegradable poly(L-lactide)/poly( $\varepsilon$-caprolactone) and poly(L-lactide)/poly(butylenes succinateco-L-lactide) polymer blends. Journal of Applied Polymer Science, Vol.114, pp.17841792.

Vilay, V., Mariatti, M., Ahmad, Z., Pasomsouk, K., Todo, M.(2010). Improvement of microstructure and fractured property of poly(L-lactic acid) and poly(butylene succinate-co- $\varepsilon$-caprolactone) blend compatibilized with lysine triisocyanate. Engineering Letters, Vol.18, No.3, pp.303-307.

Yamane, A., Sawai, D., Kameda, T., Kanamoto, T., Ito, M., Porter, R.S. (1997). Development of high ductility and tensile properties upon two-stage draw of ultrahigh molecular weight poly(acrylonitrile). Macromolecules, Vol.30, No.14, pp.4170-4178. 


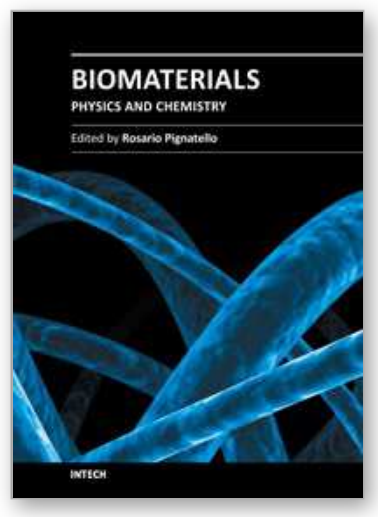

\author{
Biomaterials - Physics and Chemistry \\ Edited by Prof. Rosario Pignatello
}

ISBN 978-953-307-418-4

Hard cover, 490 pages

Publisher InTech

Published online 14, November, 2011

Published in print edition November, 2011

These contribution books collect reviews and original articles from eminent experts working in the interdisciplinary arena of biomaterial development and use. From their direct and recent experience, the readers can achieve a wide vision on the new and ongoing potentialities of different synthetic and engineered biomaterials. Contributions were selected not based on a direct market or clinical interest, but based on results coming from very fundamental studies. This too will allow to gain a more general view of what and how the various biomaterials can do and work for, along with the methodologies necessary to design, develop and characterize them, without the restrictions necessarily imposed by industrial or profit concerns. The chapters have been arranged to give readers an organized view of this research area. In particular, this book contains 25 chapters related to recent researches on new and known materials, with a particular attention to their physical, mechanical and chemical characterization, along with biocompatibility and hystopathological studies. Readers will be guided inside the range of disciplines and design methodologies used to develope biomaterials possessing the physical and biological properties needed for specific medical and clinical applications.

\title{
How to reference
}

In order to correctly reference this scholarly work, feel free to copy and paste the following:

Mitsugu Todo and Tetsuo Takayama (2011). Fracture Mechanisms of Biodegradable PLA and PLA/PCL Blends, Biomaterials - Physics and Chemistry, Prof. Rosario Pignatello (Ed.), ISBN: 978-953-307-418-4, InTech, Available from: http://www.intechopen.com/books/biomaterials-physics-and-chemistry/fracturemechanisms-of-biodegradable-pla-and-pla-pcl-blends

\section{INTECH}

open science | open minds

\section{InTech Europe}

University Campus STeP Ri

Slavka Krautzeka 83/A

51000 Rijeka, Croatia

Phone: +385 (51) 770447

Fax: +385 (51) 686166

www.intechopen.com

\section{InTech China}

Unit 405, Office Block, Hotel Equatorial Shanghai

No.65, Yan An Road (West), Shanghai, 200040, China 中国上海市延安西路65号上海国际贵都大饭店办公楼 405 单元

Phone: +86-21-62489820

Fax: $+86-21-62489821$ 
(C) 2011 The Author(s). Licensee IntechOpen. This is an open access article distributed under the terms of the Creative Commons Attribution 3.0 License, which permits unrestricted use, distribution, and reproduction in any medium, provided the original work is properly cited. 